\title{
The Study on the Key Elements in Strategic HRM: from Strategy to Organizational Performance
}

\author{
Yunlan $\mathrm{He}$
}

China State Key Laboratory of Coal Resources and Safety Mining, China University of Mining \& Technology, Beijing, 100083, China Corresponding Email: 151023631@qq.com

\begin{abstract}
Ever since the end of last century, strategic HRM scholars have devoted a great and increasing deal of efforts to the exploration and examination of contributions of HRM practices/systems into organizational performance. In spite of the lack of a conclusive message about the HRM-performance relationship, the current literature has documented vast of the evidence, which worth reviewing and may generate inspirations for future research. Thus, this research reviews the literature and teases out the key elements in strategic HRM research. These elements can be further categorized into several sub-groups: namely, HRM systems, business strategy, external and internal organizational contextual factors. Specifically, HRM systems include high control work systems, high commitment work systems, high involvement work systems, high performance work systems, high reliability work systems, and customer servicesoriented work systems. The strength of the relationships between these HRM systems and performance will be varied by the changes of business strategies and organizational contextual factors. This study reviews the five types of fits between the key elements in strategic HRM literature. Moreover, it has been argued and proved that the fits between the key elements will results in better organizational performance. This article can generate not only theoretical implications for scholar, who attempt to deepen our understanding of the mechanism through which HRM systems improve organizational performance, but practical implications for managers, who will be able to identify the key factors impacting their effectiveness in managing people in real world.
\end{abstract}

\section{Introduction}

As cross-over study of strategic management and human resource management (HRM), strategic HRM means a series of planed and strategic human resources deployment and management behaviours in order to realize goal of enterprises ${ }^{[1]}$. As a whole, the research in this field involves various factors or variables. This paper has two purposes, the first one is summarizing and teasing main factors and variables involving in research of strategic HRM; and the second one is summarizing these variables how to interact and influence performance of organization. Main factors or variables involving in research of strategic HRM can be divided into HRM system, organizational strategy, organizational performance, and internal and external environment of organization. These factors interact in different ways, and forms match (contingency) status, which realizes optimization of organizational performance.

\section{HRM system}

The style of strategic HRM has comparatively independent human resource policy and practice, and human resource bundle or human resource system, which can be categorized into 6 kinds of systems. Control mode of HRM system. proposed that control mode of HRM system was a management system to reduce direct labour costs and improve efficiency by means of improving employee's compliance level for policy and regulation, and connecting employee's compensation with labour output together ${ }^{[2]}$.

High commitment HRM system was making employee to learn the goal of organization and try to realize it by means of creating a series of conditions $\left.{ }^{[3}\right]$. These management styles included formal work team, employee involvement team and cross-team job rotation, etc. ${ }^{[4,5]}$. Huselid (1995) thought that high performance work system could improve knowledge, technology and ability of existing employees and potential employees of organization ${ }^{[6]}$. In 
empirical aspects, researchers also proved that high performance work system related to variables of organizational performance, including turnover rate of employees, financial performance, and first market performance, etc. ${ }^{[6]}$. Since occupational safety caused a great loss to enterprises and suffering to individual, it was necessary for enterprise to guarantee occupational safety, Zacharatos et al. (2005) put forward occupational safety-oriented high performance work system $^{[7]}$.

The function of customer service-oriented work system is helping employees to provide service for customers by means of creating a kind of service-oriented organization climate. Schneider et al. (1998) found that service-oriented organization climate and subsequent evaluation results of service quality from customers depended on some basic problems $^{[8]}$. Liao and Chuang (2004) further proposed that customer service-oriented high performance work system included employee involvement, training and incentive mechanism based on evaluation ${ }^{[9]}$.

\section{Organizational strategy}

In the field of strategic HRM, people mainly pay much attention on influence of strategy to HRM and influence of match between strategy and HRM to organizational performance ${ }^{[10-12]}$. Generally, the competitive strategy proposed by Schuler based on strategic classification of Porter (1985) was widely used. In addition, there were strategic classification of Wiles and Snow (1984) and strategic framework of Wright and Snell (1991).

Miles and Snow (1984) divided organizations into 4 types: defending type, aggressive type, analytical type and reaction type. Wright and Snell (1991) thought organizations could be categorized into growth type, stable type and shrinking type. Although classification of competitive strategy owes to Schuler, one point must be explained, organization strategy classification which is most widely used in present strategic HRM, is proposed by Schuler and Jackson $(1987 \mathrm{a}, 1987 \mathrm{~b})^{[13,14]}$ on the basis of competitive strategy framework of Porter, and they described behavior characteristics of needed employees in each strategy. In total, there are 3 competitive strategies, including innovation strategy, quality commission strategy and cost saving strategy.

\section{Organizational performance}

In research of strategic HRM, organizational performance can promote HRM exactly. Meanwhile, people have strong interest on what kind of organizational performance and how organizational performance can be influenced by HRM. The first batch of models of human resource system atically described involving in organizational performance appeared in 1980s, which were proposed by Beer et al. (1985) and Fombrun et al. (1984) respectively ${ }^{[15,16]}$. Models of Beer, etc, also were called Harvard Models. They though that HRM policy influenced effect of human resource firstly and further produced some long-term effects and promoted input-output rate. These long-term effects included individual welfare of employees, organizational efficiency and social welfare. Fombrun et al. (1984) put forward a socalled individual circling model of human resource ${ }^{[16]}$. The content of human resource involving in organizational performance relationship was 4 kinds of key HRM policies and practices, including selection, remuneration, evaluation and training, which promoted both individual performance and organizational performance.

\section{Internal and external environment of organization}

As BudhwarandAryee (2008) had pointed out that the most important contextual factors of organization was influence of economic, technology, social and political factors to human resource which should be mainly considered in research of strategic $\mathrm{HRM}^{[17]}$. Thus it can be seen the significance of organization and environmental factors in strategic HRM. Jackson and Schuler (1995) proposed it systematically in research of strategic HRM ${ }^{[18]}$. They unified organizational variables and environment variables to contextual variables of organization. These variables were divided into internal contextual variables and external contextual variables of organization.

\subsection{Internal contextual variables of organization}

At present, there are 6 forms of ownership in China, including state-owned enterprises, private enterprises, collectivelyowned enterprises, joint venture companies and foreign-owned companies ${ }^{[19]}$. Furthermore, township enterprises exist, although township enterprises belong to collectively-owned enterprises, their corporate structure and governance situation are greatly different from other collectively-owned enterprises'.

According to institutionalism opinion, a series of management activities adopted in forming stage of organization would be internalized in organization, and had deep influence to future development of organization. In China, age of organization related to forms of ownership. For example, age of state-owned enterprises would be older than age of joint venture enterprises or foreign-owned enterprises ${ }^{[20]}$. In a number of empirical studies, size of organization would influence style and effectiveness of HRM significantly, especially in growing and transforming stage of organization. Since the size of organization was larger, the structure would be unwieldy comparatively, organizational inertia would be greater, and further hindered the transformation process of organization ${ }^{[20]}$. This factor was proposed by, and they suggested that internal technical level of organization should be considered in research of strategic HRM. Meanwhile, 
internal technical level should be a determinant factor in choosing pattern of HRM. In different life cycle stages, such as initial period, growth stage, mature stage and decline stage, organization needs different support of HRM effect. Therefore, life cycle of organization was an important influencing factor in $\mathrm{HRM}^{[18]}$.

\subsection{External contextual variables of organization}

The technological change here means changes in macro level. In Hongkong companies they surveyed, Fields et al (2000) found that pressure caused by technological change significantly influenced core strategic position of HRM department ${ }^{[21]}$.

Industry means a group of production or profit organization sets with same characteristics. Jackson and Schuler (1995) indicated that difference of industry would influence HRM of enterprises ${ }^{[18]}$. Boxall and Purcell (2008) divided industry change into 3 phases: confusion of early establishment, mature and regenerative confusion ${ }^{[22]}$. An enterprise will pay more attention on cultivation of sustainable competitive advantages when it's competitive pressure is higher. In Hongkong companies they surveyed, Fields et al (2000) found that competitive pressure would greatly influence enterprise to adopt what kind of human resource strategy ${ }^{[21]}$. The influence of legal factors to HRM mainly reflected in utilization of laws and regulations, such as Labour Law, Environmental Protection Law, and Tax Law, etc. ${ }^{[18]}$. Political factors mainly reflect in political stability and political risks. The political stability can bring confidence to enterprises for long-range program.

Many theoretical and empirical studies proved that labour union would influence HRM. For example, in China, the existence of labour union can't significantly promote enterprise to adopt innovative strategic ${ }^{[23]}$. On the other hand, western scholars Ramaswamy and Schiphorst (2000) found that the existence of labour union would suppress organization on the contrary, especially when management staffs of organization tried innovative management activities $^{[24]}$.

In aspect of geographical location, the management mode of HRM was more refined in relatively developed areas, but in underdeveloped areas, the management mode of HRM trended to traditional personnel management mode ${ }^{[21]}$. The most popular measurement framework of national culture was proposed by Hofstede $(1980)^{[25]}$. Wallach (1983)classified company culture into bureaucrat type, innovative type and supporting type. In field of strategic HRM, Jackson and Schuler (1995) pointed out very few people directly studied influence of culture to HRM, while most people compared difference of HRM between two countries or areas, and thus thought culture would influence mode of $\mathrm{HRM}^{[18]}$.

\section{Matching: road to improvement of organizational performance}

Main research purpose of strategic HRM is verifying the positive influence of HRM system to corporate performance, and the level of influence even is influenced by organizational strategy, internal and external environment of organization. In functions of this system, match of each factor has decisive function.

Chenevert and Tremblay (2009)classified match in strategic HRM into 5 types: environment match, longitudinal match, internal match of organization, internal match of human resource system and internal activity match in subfunction of $\mathrm{HRM}^{[26]}$. Environment match emphasizes match between HRM policy and external environment of organization. According to this view, HRM system should adapt characteristics of social, cultural and legal factors. Longitudinal match emphasizes connection between human resource and organizational strategy, considers HRM system should be adjusted timely for supporting realization on strategic target of organization. Internal match of organization means match between HRM system and other internal systems of organization, such as technological level, structure, production system and organizational culture. Internal match of human resource system means match of different functions in HRM system, for example, training and development functions should match with salary management. Internal activity match in sub-function of HRM means match of policy, activity and concrete actionin each function of HRM, for example, the internal policies, activities and concrete actions of human resource recruitment and selection should match. Only when these factors match in different ways, strategic HRM policy and practice will produce significant and positive influence to organizational performance.

\section{Conclusions}

This paper teases present important factors involving in research of strategic HRM from China and the West, reviews main factors in previous research of strategic HRM, and classified these factors into HRM system, organizational strategy, internal and external environment of organization. The relationship strength between HRM system and organizational performance will change with changes of organizational strategy and internal and external environment of organization. The match level of each factor in strategic HRM will improve influence of HRM system to organizational performance. Through the study, on the one hand, in management research, researchers can further explore important variables that are not involved, and deepen research on relation between variables. On the other hand, in management practice, administrator should pay more attention on influence of these factors in whole management process, attach importance influence caused by changes of these factors in management decision and execution, 
reasonably enlarge positive influence, and try to avoid negative influence of these factors, for improving organizational performance in maximum limitation.

\section{Acknowledgement}

This research is supported by Youth Fund of Natural Science Foundation of China (41602168), Postdoctoral Fund of China (2016M591286), and Research Project for Oil and Gas Centre of China Geological Survey (12120115102101).

\section{References}

1. P. M.Wright, G. C.McMahan, B.McCormick and W. S.Sherman. Strategy, Core Competence, and HR Involvement as Determinants of HR Effectiveness and Refinery Performance, Human Resource Management, 37,1 (1998)

2. J. B.Arthur. 'The Link between Human Resource Systems on Manufacturing Performance', Academy of Management Journal, 37, (1994)

3. E. M.Whitener. Do "high commitment human resource practices affect employee commitment? A cross-level analysis using hierarchical linear modeling. Journal of Management, 27 (2001)

4. J. P.MacDuffie. Human resource bundles and manufacturing performance: Organizational logic and flexible production systems in the world auto industry. Industrial andLabor Relations Review, 48 (1995)

5. P.Osterman. How common is workplace transformation and who adopts it? Industrialand Labor Relations Review, 47 (1994)

6. M. A.Huselid. The impact of human resource management practices on turnover,productivity, and corporate financial performance. Academy of Management Journal, 38 (1995)

7. A. Zacharatos, J.Barling and R. D. Iverson. High-performance work systems andoccupational safety. Journal of Applied Psychology, 90 (2005)

8. B.Schneider, S. S.White, M. C.Paul. Linking service climate and customer perceptions of service quality: Test of a causal model. Journal of Applied Psychology, 83 (1998)

9. H.Liao, \& A.Chuang. A multilevel investigation of factors influencing employee service performance and customer outcomes. Academy of Management Journal, 47 (2004)

10. R. E.Miles and C. C..SnowDesigning Strategic Human Resource System. Organizational Dynamics, (1984)

11. M. E.Porter. Competitive Strategy: Techniques for Analyzing Industrial and Competitors. New York: Free Press (1980)

12. P. M.Wright and S. A.Snell. Toward an integrative view of strategic human resourcemanagement. Human Resource Management Review, 1 (1991)

13. R. S.Schuler and S. E.Jackson. Organizational Strategy and Organization Level as Determinants of Human Resource Management Practices. Human Resource Planning, 10,3 (1987a)

14. R. S.Schuler and S. E.Jackson. Linking Competitive Strategies with Human Resource Management Practices. The Academy of Management Executive, 1,3 (1987b)

15. B.M.Beer, P. R.Spector, D.Lawrence, Quinn Mills, and R. E.Walton. Human Resource Management: A General Manager's Perspective, New York: Free Press. (1985)

16. C. Fombrun and M. A. Devanna. Strategic human resource management. New York: John Wile (1984)

17. P.Budhwar and S. Aryee. An Introduction to Strategic Human Resource Management, In The Aston Centre for Human Resources (2008), Strategic Human Resource Management, Building Research-Based Practice, London: CIPD, (2008)

18. S. E.Jackson and R. S.Schuler. Understanding Human Resource Management in the Context of Organizations and Their Environment, in Rosenzweig, M. R. and Porter, L. W. (eds), Annual Review of Psychology. Palo Alto, CA: Annual Reviews, 46 (1995)

19. F. L.Cooke. HRM, Work and Employment in China. New York: Routledge (2005)

20. Z. D.Ding and S.Akhtar. The Organizational Choice of Human Resource Management Practices: A Study of Chinese Enterprise in three Cities in the PRC. The International Journal of Human Resource Management Journal, 12,6 (2001)

21. D. Fields, A.Chan and S. Akhtar. Organizational context and human resource management strategy: a structural equation analysis of Hong Kong firms. The International Journal of Human Resource Management, 11,2 (2000)

22. P. Boxall and J. Purcell. Strategy and Human Resource Management, New York: Palgrave Macmillan. (2008)

23. I.Ng and D.Maki. Trade Union Influence on Human Resource Management Practices. Industrial Relations, 33 (1994) 
24. E.A.Ramaswamy and F. B.Schiphorst. International Journal of Human Resource Management. 11,4 (2000)

25. G.Hofstede. Culture's Consequences: International Differences in Work-Related Values. Berverly Hills, CA: Sage. (1980)

26. D.Chenevert and M.Tremblay. Fits in Strategic Human Resource Management and Methodological Challenge: Empirical Evidence of Influence of Empowerment and Compensation Practices on Human Resource Performance in Canadian Firms. The International Journal of Human Resource Management, 20,4 (2009) 